p.s.i./nitrogen. The simulation of space conditions will not, of course, be complete, for the trial will take place on the ground where both men and system will operate under normal gravity.

The Soviet experiment has already taken place and lasted the full period of 70 days during which a medical doctor, an engineer and a journalist remained shut up together under cramped and uncomfortable conditions. The exact dimensions of the isolation chamber are not given, but it is described as small. All three subjects were thoroughly instrumented for the measurement of their physical condition during the test. Their regime was to fulfil a daily routine of work, eating, sleep and medical examination up till about the halfway stage when they switched to a "free" routine, doing as they pleased. The journalist of the group recorded reactions in his log at the end of the first three weeks: "Watch-keeping, dinner, medical examination, sleep-our life has acquired a feverish though monotonous rhythm. There is almost no free time left. But we are already beginning to teel exhausted. Stanislav [the doctor] is getting thinner, there is a stubble of beard on his cheeks and dark rings under his eyes. Leonard's eyes have become red and anxious. I cannot escape the feeling that some pungent fog is erecping into our tiny room. While gradually poisoning our brains, it makes us more intolerant towards one another".

But during the later period when there was no set routine, things scemed even worse. There was no longer a work schedule, but the men could pass the time as they chose-playing chess, reading or presumably sleeping. (Food preparation did not amount to much of a task as their diet was a typical space diet of dehydrates, concentrates, and tinned foods.) Now, they reported, time passed more slowly and nervous tension increased. Sleep was troubled and they had hallucinations of sound. They dreamt of music, singing and the noise of aircraft. None the less, no member of the group "deviated from the programme or complained"-complaint presumably being defined as a request for release from the experiment. The experimenter in charge comments that the trial was above all a test of character and willpower, but much useful information was gleaned.

\section{Mapping in Metric Units}

ONE organization faced with a formidable task in changing to metric units is the Ordnance Survey. Among proposals which have so far been endorsed by the Joint Standing Committee in accomplishing this task are that heights will be shown in metres instead of feet on new and revised maps at $1: 1,250$ and $1: 2,500$ scales. Areas will be shown in hectares instead of acres on maps at $1: 2,500$ scale. Heights will be given in metres instead of feet on bench mark lists prepared from new levelling. Contours will be shown at a metric interval on new six-inch maps. Finally, the problems of changing the six-inch and one-inch maps to "rational" scales such as $1: 10,000$ and $1: 50,000$ will be reviewed. These proposals were circulated to 180 interested bodies, representing all classes of map users.

According to the annual report of the Survey for 1966-67 (HMSO, 7s. 6d.), in which these facts are published, the past year was marked by a change of ministry. In February the responsibility for the Ordnance Survey was passed from the War Office to the Minister of Housing and Local Government. Overall expenditure during the year was $£ 5,715,000$-about one-third of which was recovered by revenue from sales of maps and from royalties. On the whole, how. ever, there was a falling off in demand for maps, which, the report suggests, is mainly due to the deferment of investment in development schemes in many parts of the country as a result of the Government's economic measures, together with an increase in the price of maps at certain scales. On March 31, the total number of staff was 4,090 non-industrial and 552 industrial compared with 4,008 and 540 a year earlier-a vigorous recruiting programme bringing in some 480 new staff.

Survey of the principal town areas on the scale of $1: 1,250$ is said in the report to be nearing completion and revision of the old 1 : 2,500 plans covering minor towns and rural areas has been speeded up, largely through the increased use of aerial photographs. Instead of the five-year re-levelling programme which was originally aimed at, subsidence areas will be levelled on a twenty-year cycle as in normal areas.

\section{New Physics Symbol}

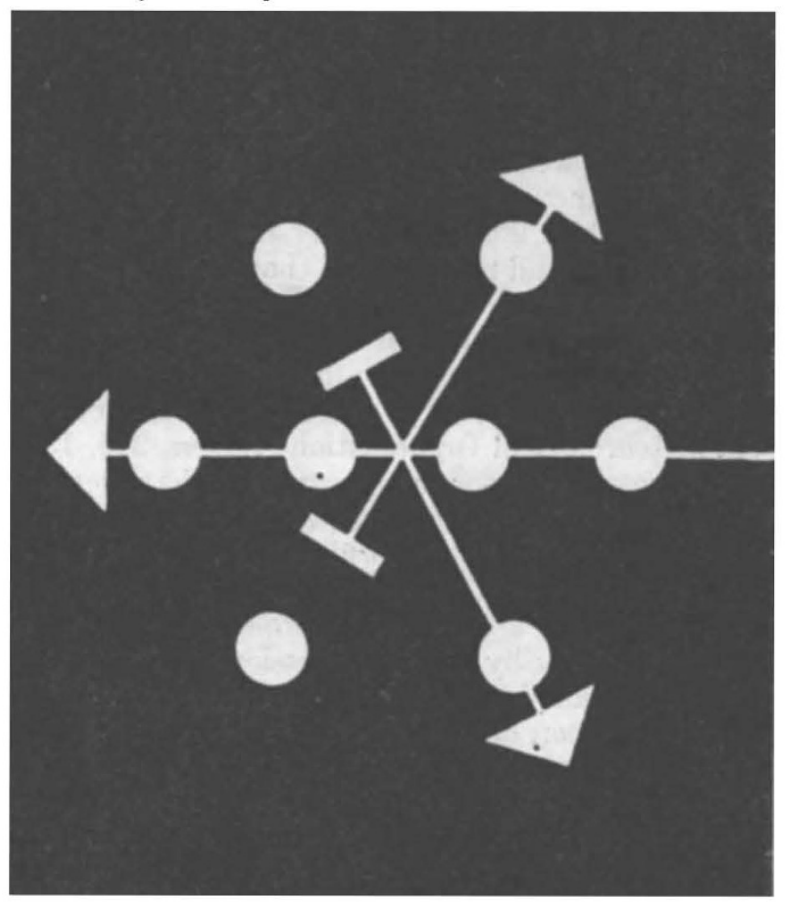

THe Institute of Physics and the Physical Society hopes that this symbol, when correctly placed on a red ground, will soon become familiar to anyone who has any aequaintance with physics. The symbol has been designed to accompany all kinds of information produced in connexion with the four-day Physics Exhibition opening at the Alexandra Palace on March 11. It is based on the weight diagram for the irreducible representation $D^{8}(1,1)$ of the $S U(3)$ symmetry which has been successful in bringing order to the classification of sub-atomic particles. Mr D. Walter, who is organizing the exhibition, first thought of basing the symbol on $S U(3)$ symmetry and, after advice from Imperial College, the final representation was drawn by Mr M. R. Preston of the Science Museum. 